\title{
PENGARUH PELATIHAN KERJA DAN DISIPLIN KERJA TERHADAP KINERJA KARYAWAN PADA KOPERASI SIMPAN PINJAM (KSP) SAHABAT MITRA SEJATICABANG RIMBO BUJANGKABUPATEN TEBO
}

\author{
Herawati, Wanda Madyatama \\ Program Studi Manajemen Fakultas Ekonomi \\ Universitas Muara Bungo
}

\begin{abstract}
ABSTRAK
Tujuan dilakukan penelitian ini adalah untuk mengetahui pengaruh pelatihan kerja dan disiplin kerja terhadap kinerja karyawan pada koperasi simpan pinjam sahabat mitra sejati cabang rimnbo bujang kabupaten tebo. Metode penelitian ini bersifat kuantitatif dengan analisis Regresi Linear Berganda. Populasi dalam penelitian berjumlah 30 orang. Sedangkan sampel dalam penelitian berjumlah 30 orang.

Hasil penelitian ini, uji regresi linier berganda diperoleh nilai $\mathrm{Y}=16,697+0,225$ $+0,733+$ e. $\mathrm{Uji}\left(\mathrm{X}_{1}\right)$ didapatkan nilai $\mathrm{t}_{\text {hitung }}(1.790)>\mathrm{t}_{\text {tabel }}(2.051)$, dan $\left(\mathrm{X}_{2}\right)$ didapatkan nilai $t_{\text {hitung }}(3,331)<t_{\text {tabel }}(2.051)$, sehingga $H_{0}$ ditolak dan $h_{a}$ diterima. Artinya, secara parsial pelatihan kerja dan disiplin kerja berpengaruh terhadap kinerja pegawai berdasarkan nilai $F_{\text {hitung }} 9.732>$ dari pada $F_{\text {tabel }}$ sebesar 3.35. Sehingga variabel pelatihan kerja dan disiplin kerja secara simultan berpengaruh positif dan signifikan terhadap kinerja pegawai. Berdasarkan hasil pengolahan data diketahui bahwa pengaruh variabel disiplin kerja dan pelatihan kerja ebesar 37,6\%, secara bersama-sama terhadap besarnya variasi (naik turun) variabel terikat. Sedangkan sisanya sebesar 62,4\% dipengaruhi oleh dimensi lain diluar penelitian ini.
\end{abstract}

KATA KUNCI : Pelatihan Kerja, Disiplin Kerja, Kinerja Karyawan.

\section{PENDAHULUAN}

Organisasi

merupakan perkumpulan atau wadah bagi sekelompok orang untuk bekerjasama, terkendali dan terpimpin untuk tujuan tertentu. Organisasi biasanya memanfaatkan suatu sumber daya tertentu misalnya lingkungan, cara atau metode, material, mesin, uang, dan beberapa sumber daya lain dalam rangka mencapai tujuan organisasi tersebut. Orang - orang yang berkumpul dalam sebuah organisasi sepakat untuk mencapai tujuan tertentu melalui sumber daya secara sistematis dan rasional yang terkendali dan adanya pemimpin organisasi yang akan memimpin operasional dengan terencana. Tingkat keberhasilan suatu organisasi dalam melakukan segala kegiatan untuk mencapai tujuan sangat bergantung kepada kemampuan sumber daya manusianya dalam melakukan aktivitas.

Kinerja karyawan merupakan salah satu faktor utama dalam keberhasilan perusahaan untuk terus tumbuh dan berkembang serta dapat bersaing dengan perusahaan lainnya. Kinerja karyawan yang baik tentunya tidak lepas dari berbagai faktor yang mempengaruhi sumber daya manusia di dalam perusahaan. Faktor tersebut antara lain pelatihan kerja dan disiplin kerja.

Pelatihan merupakan bentuk nyata yang dapat dilakukan oleh perusahaan untuk meningkatkan mutu karyawan.Pelatihan ini juga diperlukan agar karyawan semakin termotivasi untuk secara terus menerus berusaha untuk meningkatkan produktivitaskerjanya, minimal sesuai dengan yang ditentukan oleh perusahan. Hal ini diperlukan untuk 
meningkatkan daya saing perusahaan dengan perusahaan lain yang sejenis.

Selain pelatihan, disiplin kerja merupakan modal yang penting yang harus dimiliki oleh karyawan dalam meningkatkan kinerjanya. Namun, kualitas etos kerja dan disiplin kerja karyawan di Indonesia secara umum masih tergolong rendah, ini disebabkan banyaknya permasalahan yang dihadapi oleh para karyawan. Dalam upaya meningkatkan kedisiplinan karyawan sebenarnya perusahaan telah memberikan suatu regulasi dengan mengeluarkan aturan aturan tentang disiplin kerja untuk meningkatkan kinerja karyawan sebagai pelaksana utama operasional perusahaan.

Koperasi Simpan Pinjam Sahabat Mitra Sejati Cabang Rimbo Bujang Kabupaten Tebo adalah badan hukum berbentuk koperasi yang bergerak dalam bidang usaha simpan pinjam.Koperasi Simpan Pinjam Sahabat Mitra Sejati hadir untuk menyentuh secara langsung perekonomian mikro di Kabupaten Tebo.Koperasi Simpan Pinjam Sahabat Mitra Sejati bertujuan untuk meningkatkan hubungan baik dengan masyarakat, para pengusaha kecil mikro.

Koperasi Simpan Pinjam Sahabat Mitra Sejati melayani seperti :

1. Simpananseperti Tabungan Sahabat, Simpanan Berjangka.

2. Pinjaman Usaha seperti Pembiayaan Mikro, Pembiayaan Pedagang, Pembiayaan Kelapa Sawit, Pembiayaan Flexible.

3. Pinjaman Konsumtif seperti Pembiayaan Pemilikan Sepeda Motor, Pembiayaan Pemilikan Mobil.

Berikut jumlah karyawan Koperasi Simpan Pinjam Sahabat Mitra Sejati Cabang Rimbo Bujang Kabupaten Tebo sebanyak 30 orang. Berikut rinciannya :

\begin{tabular}{|c|l|c|}
\hline No & \multicolumn{1}{|c|}{ Karyawan } & Jumlah \\
\hline 1 & Branch Manager (Pimpinan Cabang) & 1 \\
\hline 2 & Financing Officer & 4 \\
\hline 3 & Sahabat Usaha & 14 \\
\hline 4 & Collection $\quad$ Jumlah Total & 11 \\
\hline & \multicolumn{1}{|c|}{30} \\
\hline
\end{tabular}

Sumber Data : KSP Sahabat Mitra Sejati Cabang Rimbo Bujang, 2019

Berdasarkan Tabel di atas terdapat 4 jabatan di Koperasi Simpan Pinjam Sahabat Mitra Sejati Cabang Rimbo Bujang Kabupaten Tebo yaitu Branch Manager, Financing Officer, Sahabat Usaha, dan Collection. Branch Manager bertugas sebagai seorang pimpinan di cabang yang bertanggung jawab untuk mengoordinasi dan mengawasi operasi cabang termasuk perekrutran atau pengawasan. Financing Officer bertugas menganalisa layak atau tidaknya memberikan pinjaman kepada nasabah sesuai usaha yang dimilikinya. Sahabat Usaha bertugas untuk mencairkan dana sesuai perintah dari Financing Officer. Collection bertugas untuk mengumpulkan dana yang sudah dipinjamkan oleh nasabah. 


\section{Data Karyawan Yang Mengikuti Pelatihan Koperasi Simpan Pinjam Sahabat Mitra} Sejati Cabang Rimbo BujangKabupaten Tebo

\begin{tabular}{|c|l|c|l|c|}
\hline No & \multicolumn{1}{|c|}{ Jenis Pelatihan } & $\begin{array}{c}\text { Jumlah } \\
\text { Karyawan }\end{array}$ & Tempat Pelatihan & Waktu \\
\hline 1 & $\begin{array}{l}\text { Selling Skill } \\
\text { (Keterampilan } \\
\text { Menjual) }\end{array}$ & 30 & $\begin{array}{l}\text { Kantor Koperasi } \\
\text { Simpan Pinjam } \\
\text { Sahabat Mitra } \\
\text { Sejati Jambi }\end{array}$ & $\begin{array}{c}\text { Sekali } \\
\text { Setahun }\end{array}$ \\
\hline 2 & $\begin{array}{l}\text { Negotation Skill } \\
\text { (Keterampilan } \\
\text { Negosiasi) }\end{array}$ & 30 & $\begin{array}{l}\text { Kantor Koperasi } \\
\text { Simpan Sahabat } \\
\text { Mitra Sejati }\end{array}$ & $\begin{array}{c}\text { Sekali } \\
\text { Setahun } \\
\text { Pekanbaru }\end{array}$ \\
\hline 3 & $\begin{array}{l}\text { Mindset Skill } \\
\text { (Keterampilan Pola } \\
\text { Pikir) }\end{array}$ & 30 & $\begin{array}{l}\text { Kantor Koperasi } \\
\text { Simpan Sahabat } \\
\text { Mitra Sejati Padang }\end{array}$ & Setahun \\
\hline 4 & $\begin{array}{l}\text { Personal Effectiveness } \\
\text { (Keefektifan Pribadi) }\end{array}$ & 30 & $\begin{array}{l}\text { Kantor Koperasi } \\
\text { Simpan Pinjam } \\
\text { Sahabat Mitra } \\
\text { Sejati Palembang }\end{array}$ & Sekali \\
& & & Setahun \\
\hline
\end{tabular}

Sumber Data : KSP Sahabat Mitra Sejati Cabang Rimbo Bujang, 2019

Berdasarkan Tabel di atas terlihat jenis pelatihan seperti Selling Skill, Negotation Skill, Mindset Skill, Personal Effectiveness masing-masing yang mengikuti pelatihan tersebut berjumlah 30 orang dengan tempat areapelatihan yang berbeda-beda, dimana seluruh kantor cabang area jambi seperti Sarolangun, Bangko, Muara Bungo, Singkut, Rimbo Bujang, Jelutung, Muara Tembesi, Sungai Bahar, Bayung Lincir dan Talang Banjar ikut serta dalam mengikuti pelatihan, tidak hanya pelatihan mereka juga sekalian Outing dan Meeting.

Rekapitulasi Absensi Karyawan Bulan Agustus - Desember Tahun 2019 Koperasi Simpan Pinjam Sahabat Mitra Sejati Cabang Rimbo Bujang

Kabupaten Tebo

\begin{tabular}{|c|c|c|c|c|c|c|c|c|c|}
\hline \multirow{2}{*}{ No } & \multirow{2}{*}{ Bulan } & \multirow{2}{*}{$\begin{array}{c}\text { Jumlah } \\
\text { Karyawan }\end{array}$} & \multirow{2}{*}{$\begin{array}{l}\text { Hari } \\
\text { Kerja }\end{array}$} & \multicolumn{4}{|c|}{ Ketidakhadiran } & \multirow{2}{*}{$\begin{array}{c}\text { Jumlah } \\
\text { Hari Absen }\end{array}$} & \multirow{2}{*}{ Presentase } \\
\hline & & & & $\mathbf{A}$ & I & $\mathbf{S}$ & $\mathbf{C P}$ & & \\
\hline 1 & Agustus & 30 & 22 & - & 4 & - & - & 4 & $5,45 \%$ \\
\hline 2 & September & 30 & 21 & 2 & - & 2 & - & 4 & $5,71 \%$ \\
\hline 3 & Oktober & 30 & 23 & - & - & 1 & - & 1 & $1,30 \%$ \\
\hline 4 & November & 30 & 22 & - & 5 & 3 & - & 8 & $10,90 \%$ \\
\hline 5 & Desember & 30 & 21 & 4 & 2 & - & - & 6 & $8,57 \%$ \\
\hline \multicolumn{4}{|c|}{ Rumus : Absensi $=\frac{J H A}{J H K X J K} \times 100 \%$} & & & & & Rata-Rata & $6,38 \%$ \\
\hline
\end{tabular}

Sumber Data : KSP Sahabat Mitra Sejati Cabang Rimbo Bujang, 2019

Keterangan : 


$\begin{array}{lllll}\text { A : } & \text { Alpha } & \text { JHK } & : & \text { Jumlah Hari Kerja } \\ \text { I }: & \text { Izin } & \text { JHA } & : & \text { Jumlah Hari Absen } \\ \text { S : } & \text { Sakit } & \text { JK }: & \text { Jumlah Karyawan } \\ \text { CP: } & \text { Cepat Pulang } & & & \end{array}$

Berdasarkan Tabel di atas kehadiran karyawan sudah terlihat sangat baik hal tersebut terlihat dari absensi karyawan dari 5 bulan terakhir yakni di bulan Agustus sampai Desember, hanya saja permasalahan karyawan di perusahaan tersebut ialah masih banyak karyawan yang cenderung menunda pekerjaannya dan memanfaatkan waktu lebih dari jam istirahat yang telah ditentukan.

Kebijakan yang dilakukan oleh Branch Manager apabila karyawan yang melanggar peraturan seperti tidak memanfaatkan jam kerja dengan sebaik - baiknya, seperti masih banyak karyawan yang duduk diluar pada saat jam kerja, mengobrol diruangan serta makan dan minum pada waktu istirahat telah habis maka karyawan akan diberi surat peringatan pertama dan apabila karyawan melanggar sampai ketiga kalinya maka karyawan tersebut akan dikeluarkan dariperusahaan tersebut. Tetapi, apabila karyawan tersebut telah mencapai target pencapaiannya maka akan diperbolehkan istirahat pada saat jam kerja.

\section{Data Kinerja Karyawan Bulan Agustus - Desember Tahun 2019 Koperasi Simpan Pinjam Sahabat Mitra Sejati Cabang Rimbo BujangKabupaten Tebo}

\begin{tabular}{|c|c|c|c|}
\hline No & Bulan & Pencairan ke Nasabah & Penagihan ke Nasabah \\
\hline 1 & Agustus & $4,067 \mathrm{M}$ & $89.09 \%$ \\
\hline 2 & September & $3,101.5 \mathrm{M}$ & $87.98 \%$ \\
\hline 3 & Oktober & $2,461.5 \mathrm{M}$ & $88.22 \%$ \\
\hline 4 & November & $2,506 \mathrm{M}$ & $86.68 \%$ \\
\hline 5 & Desember & $3,127 \mathrm{M}$ & $88.12 \%$ \\
\hline
\end{tabular}

Sumber Data : KSP Sahabat Mitra Sejati Cabang Rimbo Bujang, 2019

Berdasarkan Tabel di atas terlihat
bahwa adanya peningkatan serta
penurunan hasil kinerja karyawan Peningkatan hasil kinerja karyawan disebabkan oleh adanya pelatihan kerja dan disiplin kerja, sedangkan penurunan hasil kerja disebabkan olehmasih banyak karyawan yang cenderung menunda pekerjaannya dan memanfaatkan waktu lebih dari jam istirahat yang telah ditentukanpada Koperasi Simpan Pinjam Sahabat Mitra Sejati Cabang Rimbo Bujang Kabupaten Tebo.

Berdasarkan pengamatan langsung pra penelitian di Koperasi Simpan Pinjam Sahabat Mitra Sejati Cabang Rimbo Bujang Kabupaten Tebo bahwa kinerja karyawan di Koperasi Simpan Pinjam tersebut belum cukup memadai dalam melaksanakan tugas dan kewajibannya dalam bekerja. Hal tersebut disebabkan oleh kurangnya pelatihan dan disiplin karyawan dalam bekerja seperti masih banyak karyawan yang suka menunda pekerjaannya sehingga karyawan tersebut tidak dapat menyelesaikan pekerjaan sesuai dengan ketentuan waktu yang sudah ditetapkan, mengakibatkan banyaknya pekerjaan yang menumpuk dan berdampak pada hasil kerja.

\section{KAJIAN PUSTAKA Pelatihan Kerja}

Menurut Mangkunegara (2006), pelatihan adalah suatu proses jangka pendek yang mempergunakan prosedur sistematik dan 
terorganisir dimana pegawai non manajerial mempelajari pengetahuan dan keterampilan teknis dalam tujuan terbatas. Menurut Widodo (2015:82), pelatihan merupakan serangkaian aktivitas individu dalam meningkatkan keahlian dan pengetahuan secara sistematis sehingga mampu memiliki kinerja yang profesional dibidangnya, pelatihan adalah proses pembelajaran yang memungkinkan pegawai melaksanakan pekerjaan yang sekarang sesuai dengan standar.

Dari beberapa pengertian diatas dapat disimpulkan pelatihan adalah sebuah proses untuk meningkatkan kompetensi karyawan dan dapat melatih kemampuan, keterampilan, keahlian, dan pengetahuan karyawan guna melaksanakan pekerjaan secara efektivitas dan efisien untuk mencapai tujuan di suatu perusahaan.

\section{Disiplin Kerja}

Sutrisno (2009) disiplin kerja adalah perilaku seseorang yang sesuai dengan peraturan, prosedur kerja yang ada atau disiplin kerja adalah sikap, tingkah laku dan perbuatan yang sesuai dengan peraturan dari organisasi baik tertulis maupun tidak tertulis. Nitisemito (1996) disiplin adalah suatu sikap tingkah laku dan perbuatan yang sesuai dengan peraturan dari perusahaan baik yang tertulis maupun yang tidak tertulis.Menurut pendapat Handoko (dalam Wirawan, 1994) disiplin adalah kegiatan manajemen untuk menjalankan standarstandar organisasional.

Berdasarkan dari pendapat para ahli diatas dapat disimpulkan bahwa disiplin kerja adalah suatu sikap atau perilaku karyawan sebagai suatu upaya untuk meningkatkan kesadaran dan kesediaan seseorang mentaati semua peraturan perusahaan dan norma-norma yang berlaku.

\section{Kinerja Karyawan}

Kinerja merupakan capaian atau hasil kerja dari seorang karyawan dalam menyelesaikan tugas yang dibebankan kepadanya dengan kurun waktu tertentu dalam suatu perusahaan atau bidang yang digelutinya, sehingga kinerja karyawan yang berkualitas sangatlah dibutuhkan untuk dapat memberikan konstribusi yang maksimal untuk perusahaan, sebab hal itu sangatlah berpengaruh bagi kemajuan perusahaan.

Menurut Robbins (2006) kinerja merupakan pencapaian yang optimal sesuai dengan potensi yang dimiliki seorang karyawan merupakan hal yang selalu menjadi perhatian para pemimpin organisasi.Kinerja ini menggambarkan sejauh mana aktivitas seseorang dalam melaksanakan tugas dan berusaha dalam mencapai tujuan yang ditetapkan.

Menurut Torang (2012) kinerja adalah kuantitas atau kualitas hasil kerja individu atau sekelompok di dalam organisasi dalam melaksanakan tugas pokok dan fungsi yang berpedoman pada norma, standar operasional prosedur kriteria dan ukuran yang telah ditetapkan atau berlaku dalam organisasi.

\section{METODOLOGI PENELITIAN}

Metode yang digunakan dalam penelitian ini adalah penelitian deskriptif kuantitatif yang dapat digunakan untuk meneliti pada populasi atau sampel tertentu, pengumpulan data menggunakan instrument penelitian, analisis data bersifat kuantitatif/statistik, dengan tujuan untuk menguji hipotesis yang telah ditetapkan (Sugiyono, 2012).

Adapun teknik penarikan sampel menggunakan metode Sampling Jenuh dimana anggota populasi digunakan sebagai sampel karena jumlah populasi relatif kecil (Sugiyono, 2012). Adapun jumlah sampel dalam penelitian ini sebanyak 30 orang.

Alasan pemilihan teknik sampling jenuh, dikarenakan jumlah karyawan Koperasi Simpan Pinjam Sahabat Mitra Sejati Cabang Rimbo Bujang Kabupaten Tebo yang sedikit sehingga keseluruhan populasi dijadikan sampel.Sedangkan terhadap populasi atau dapat dikatakan semakin kecil tingkat kesalahannya. Oleh karena itu, sampel yang diambil untuk penelitian ini sebanyak 30 orang 
karyawan. Jadi teknik sampling jenuh adalah teknik pengambilan sampel yang memperhatikan nilai kejenuhan sampel. Sampel jenuh juga sering diartikan sampel yang sudah maksimum, karena ditambah berapapun jumlahnya tidak akan merubah keterwakilan populasi (Sugiyono,2017).

\section{HASIL \\ PENELITIAN \\ DAN}

Uji t dalam penelitian ini dilakukan dengan tingkat signifikan $\alpha=5 \%$ Sementara nilai $t_{\text {tabel }}$ pada $\alpha=0,05: 2=$ 0,025 (uji dua sisi) dengan derajat kebebasan atau degree of freedom (df) $n-k$ dimana $\mathrm{n}=$ banyak sampel dan $\mathrm{k}=$ banyaknya variabel bebas dan terikat, maka $30-3=27$ diperoleh $t_{\text {tabel }}$ sebesar 2,051 .

\section{Hasil Uji t (Parsial)}

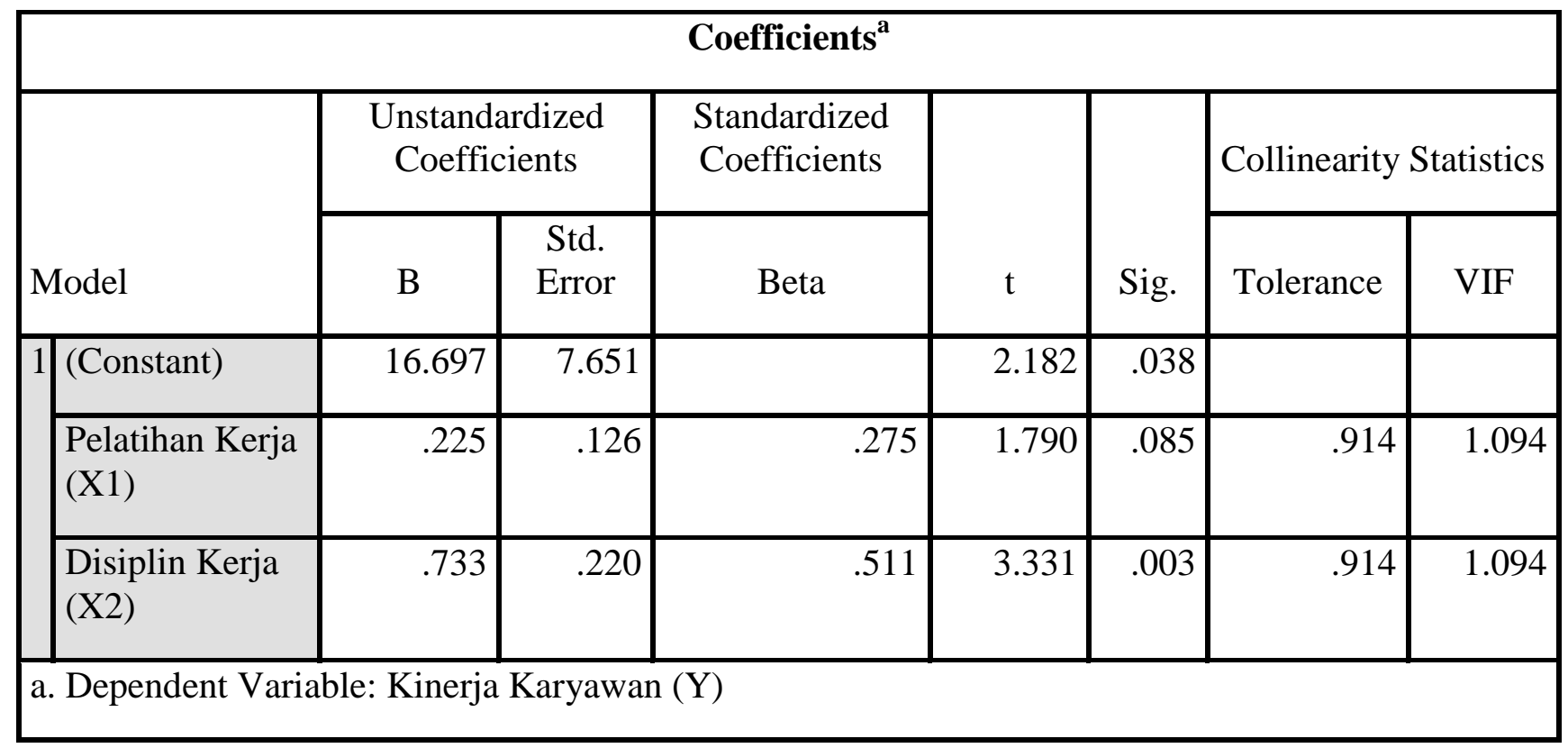

Sumber: Output SPSS (Olah data)

Berdasarkan tabel di atas dapat dijelaskan sebagai berikut :

a. Hasil uji t untuk variabel pelatihan kerja (X1)

Hasil uji parsial, variabel pelatihan kerja (X1) tidak berpengaruh signifikan terhadap kinerja karyawan (Y) Koperasi Simpan Pinjam (KSP) Sahabat Mitra Sejati Cabang Rimbo Bujang Kabupaten Tebo. Hal ini dapat terlihat dari nilai $t_{\text {hitung }}$ (1.790) $<\mathrm{t}_{\text {tabel }}$ (2.051), sehingga $\mathrm{H}_{0}$ diterima dan $\mathrm{H}_{\mathrm{a}}$ ditolak. Artinya secara parsial variabel pelatihan kerja tidak berpengaruh terhadap kinerja karyawan Koperasi Simpan Pinjam (KSP) Sahabat Mitra Sejati Cabang Rimbo Bujang Kabupaten Tebo. Hal ini dapat terjadi karena pegawai memberikan penilaian rendah pada pelatihan kerja namun memberikan penilaian tinggi pada kinerja, kondisi tersebut dapat dipahami bahwa pekerjaan yang diberikan kepada karyawan dapat diselesaikan meskipun pelatihan kerja kurang baik.

b. Hasil uji t untuk variabel disiplin kerja (X2)

Hasil uji parsial, variabel disiplin kerja (X2) berpengaruh signifikan terhadap kinerja karyawan (Y) Koperasi Simpan Pinjam (KSP) Sahabat Mitra Sejati Cabang Rimbo Bujang Kabupaten Tebo. Hal ini dapat terlihat dari nilai $t_{\text {hitung }}(3.331)<t_{\text {tabel }}$ (2.051), sehingga $\mathrm{H}_{0}$ ditolak dan $\mathrm{H}_{a}$ diterima. Artinya secara parsial variabel disiplin kerja berpengaruh terhadap kinerja karyawan Koperasi Simpan Pinjam (KSP) Sahabat Mitra Sejati Cabang Rimbo Bujang Kabupaten Tebo. Jika disiplin kerja semakin baik maka akan meningkat pula kinerja karyawan Koperasi Simpan 
Pinjam (KSP) Sahabat Mitra Sejati Cabang Rimbo Bujang Kabupaten Tebo.

\section{Hasil Uji F (Simultan)}

Uji $F$ dalam penelitian ini dilakukan dengan tingkat signifikansi $\alpha=$ 0,05 . Sementara nilai $F_{\text {tabel }}$ pada $\alpha=0,05$ df (k-1) atau 3-1 = 2, dan df $2(\mathrm{n}-\mathrm{k})$ atau $30-3=27$ (n adalah jumlah kasus atau responden dan $\mathrm{k}$ adalah jumlah variabel bebas dan terikat), diperoleh $F_{\text {tabel }}$ sebesar 3.35 .

Adapun dasar pengambilan keputusan dalam uji $\mathrm{F}$ adalah sebagai berikut: a. Jika nilai $F_{\text {hitung }} \leq \mathrm{F}_{\text {tabel }}$, maka $\mathrm{H}_{0}$ diterima dan $\mathrm{H}_{\mathrm{a}}$ ditolak, artinya variabel independen secara simultan tidak berpengaruh signifikan terhadap variabel dependen.

b. Jika nilai $\mathrm{F}_{\text {hitung }}>\mathrm{F}_{\text {tabel }}$, maka $\mathrm{H}_{0}$ ditolak dan $\mathrm{H}_{\mathrm{a}}$ diterima, artinya variabel independen secara simultan berpengaruh signifikan terhadap variabel dependen.

\begin{tabular}{|l|l|r|r|r|r|r|}
\hline \multicolumn{7}{|l|}{ ANOVA $^{\text {a }}$} \\
\hline \multicolumn{2}{|l|}{ Model } & Sum of Squares & Df & Mean Square & F & Sig. \\
\hline & Regression & 383.463 & 2 & 191.731 & 9.732 & $.001^{\text {b }}$ \\
\cline { 2 - 7 } & Residual & 531.904 & 27 & 19.700 & & \\
\cline { 2 - 7 } & Total & 915.367 & 29 & & & \\
\hline \multicolumn{7}{|l}{ a. Dependent Variable: Kinerja Karyawan (Y) } \\
\hline
\end{tabular}

Sumber: Output SPSS (Olah data)

Berdasarkan output Anova di atas dapat dilihat bahwa nilai $F_{\text {hitung }}$ adalah 9.732 lebih besar daripada $F_{\text {tabel }}$ sebesar 3.35. Sehingga $\mathrm{H}_{0}$ ditolakdan $\mathrm{H}_{\mathrm{a}}$ diterima.Maka dapat disimpulkan bahwa variabel pelatihan kerja (X1) dan disiplin kerja (X2) secara simultan berpengaruh positif dan signifikan terhadap kinerja karyawan (Y) Koperasi Simpan Pinjam (KSP) Sahabat Mitra Sejati Cabang Rimbo Bujang Kabupaten Tebo.

Koefisien Determinasi $\left(\mathbf{R}^{2}\right)$

\begin{tabular}{|l|r|r|r|r|}
\hline \multicolumn{5}{|c|}{ Model Summary } \\
\hline Model & R & R Square & Adjusted R Square & Std. Error of the Estimate \\
\hline 1 & $.647^{\mathrm{a}}$ & .419 & .376 & 4.438 \\
\hline
\end{tabular}


Berdasarkan output model summary di atas dapat dilihat nilai Adjusted $R$ Square sebesar 0,376 atau $37,6 \%$. Besarnya nilai tersebut menunjukkan proporsi pengaruh yang dapat dijelaskan oleh variabel disiplin kerja dan pelatihan kerja secara bersama sama terhadap besarnya variasi (naik turun) variabel terikat. Dimana variabel terikat (Y) dapat dijelaskan oleh kedua variabel bebas sebesar 37,6\%, sedangkan sisanya sebesar $62,4 \%$ dipengaruhi oleh dimensi lain diluar penelitian.

\section{PENUTUP}

\section{Kesimpulan}

Berdasarkan hasil penelitian dan pembahasan pada bab sebelumnya, maka dapat ditarik kesimpulan sebagai berikut:

1. Berdasarkan hasil pengolahan data, uji parsial variabel Pelatihan Kerja $\left(\mathrm{X}_{1}\right)$ didapatkan nilai $\mathrm{t}_{\text {hitung }}(1.790)<\mathrm{t}_{\text {tabel }}$ (2.051), sehingga $\mathrm{H}_{0}$ diterima dan $\mathrm{H}_{\mathrm{a}}$ ditolak. Artinya secara parsial variabel pelatihan kerja tidak berpengaruh terhadap kinerja karyawan Koperasi Simpan Pinjam (KSP) Sahabat Mitra Sejati Cabang Rimbo Bujang Kabupaten Tebo, sedangkan nilai $t_{\text {hitung }}$ (3.331) $<\mathrm{t}_{\text {tabel }}(2.051)$, sehingga $\mathrm{H}_{0}$ ditolak dan $\mathrm{H}_{\mathrm{a}}$ diterima. Artinya secara parsial variabel disiplin kerja berpengaruh terhadap kinerja karyawan Koperasi Simpan Pinjam (KSP) Sahabat Mitra Sejati Cabang Rimbo Bujang Kabupaten Tebo. Artinya jika disiplin kerja semakin baik, maka akan semakin meningkat pula kinerja karyawan Koperasi Simpan Pinjam (KSP) Sahabat Mitra Sejati Cabang Rimbo Bujang Kabupaten Tebo.

2. Berdasarkan output Anova diketahui bahwa nilai $F_{\text {hitung }}$ adalah 9.732 lebih besar daripada $\mathrm{F}_{\text {tabel }}$ sebesar 3.35 . Sehingga $\mathrm{H}_{0}$ ditolak dan $\mathrm{H}_{\mathrm{a}}$ diterima. Maka dapat disimpulkan bahwa variabel pelatihan kerja (X1) dan disiplin kerja (X2) secara simultan berpengaruh positif dan signifikan terhadap kinerja karyawan
Koperasi Simpan Pinjam (KSP) Sahabat Mitra Sejati Cabang Rimbo Bujang Kabupaten Tebo.

3. Berdasarkan output model summary didapat dilihat nilai Adjusted $R$ Square sebesar 0,376 atau 37,6\%. Besarnya nilai tersebut menunjukkan proporsi pengaruh yang dapat dijelaskan oleh variabel disiplin kerja dan pelatihan kerja secara bersama - sama terhadap besarnya variasi (naik turun) variabel terikat. Dimana variabel terikat (Y) dapat dijelaskan oleh kedua variabel bebas sebesar 37,6\%, sedangkan sisanya sebesar $62,4 \%$ dipengaruhi oleh dimensi lain diluar penelitian.

\section{Saran}

Berdasarkan kesimpulan diatas penulis memberikan saran sebagai berikut:

1. Diharapkan kepada pimpinan Koperasi Simpan Pinjam (KSP) Sahabat Mitra Sejati Cabang Rimbo Bujang Kabupaten Tebo agar lebih meningkatkan pelatihan kerja hal ini dikarenakan rendahnya nilai pelatihan kerja. Hal ini bisa dilakukan dengan cara memberikan pelatihan yang menarik untuk karyawan.

2. Diharapkan kepada pimpinan Koperasi Simpan Pinjam (KSP) Sahabat Mitra Sejati Cabang Rimbo Bujang Kabupaten Tebo agar lebih meningkatkan dan mempertahankan disiplin kerja pegawainya, hal ini bisa dilakukan dengan memberikan reward kepada pegawainya yang disiplin serta memberikan punishment terhadap pegawai yang kurang disiplin.

3. Penelitian selanjutnya disarankan untuk dapat mengembangkan model penelitian dengan penambahan variabel penelitian yang lain tentang Pengaruh Pelatihan Kerja Dan Disiplin Kerja Terhadap Kinerja Karyawan.

\section{DAFTAR PUSTAKA}


Arikunto, Suharsimi. 2006. Prosedur Penelitian Suatu Pendekatan Praktek. Jakarta : Rhineka Cipta.

Anwar Prabu Mangkunegara. 2006. Perencanaan dan Pengembangan Manajemen Sumber Daya Manusia, pen. PT Refika Aditama.

Anissa Diyana Wati. 2017. Pengaruh Pelatihan, Kompensasi dan Disiplin Kerja Terhadap Kinerja Karyawan Studi Pada PT. Eco Smart Garment Indonesia. Skripsi Institut Agama Islam Negeri Surakarta.

Aini. 2014. Kinerja karyawan. Universitas Islam Negeri Suman Ampel Surabaya.

Bagus Anindyo Spalagita. 2012. Hubungan Antar Iklim. Fakultas Psikologi Universitas Muhammadiyah Purwokerto.

Erma Safitri. 2013. Pengaruh Pelatihan dan Disiplin Kerja Terhadap Kinerja Karyawan Dinas Apron Move Crontol PT. Angkasa Pura I (Persero) Cabang Bandar Udara Internasional Juanda Surabaya. Skripsi Universitas Negeri Surabaya.

Fakultas Ekonomi Universitas Muara Bungo. 2019. Buku Panduan Pedoman Penulisan Proposal dan Skripsi. Universitas Muara Bungo.

Ghozali, Imam. 2006. Aplikasi Analisis Multivariate dengan Program SPSS (Edisi Ke 4). Semarang : Badan Penerbit Universitas Diponegoro.

Indira Lulu Marlinda. 2016. Pengaruh Pelatihan dan Disiplin Kerja Terhadap Kinerja Karyawan Bank Rakyat Indonesia (Persero) Tbk Cabang Sragen. Skripsi Universitas Muhammadiyah Surakarta.

Kaswan. 2012. Manajemen Sumber Daya Manusia. Universitas Bina Nusantara Jakarta Barat.
Mulyadi. 2017. Kinerja Pegawai. Universitas Islam Negeri Sunan Gunung Djati Bandung.

Nugraha. 2016. Pelatihan Kerja. Universitas Widyatama Bandung.

Novi. 2016. Pelatihan Kerja. Politeknik Negeri Sriwijaya Palembang.

Priyatno Duwi. 2009. SPSS Untuk Analisis Korelasi, Regresi, dan Multivariate. Yogyakarta : Gava Media.

Robbins. S.P, 2006. Perilaku Organisasi. Edisi 10, PT.Indeks Kelompok Gramedia.

Safitri Indriyanti. 2015. Pengaruh Pelatihan Kerja dan Disiplin Kerja Terhadap Produktivitas Kerja Karyawan pada PT. Paradise Island Furniture. Universitas Negeri Yogyakarta.

Siregar. 2014. Kedisiplinan. Universitas Negeri Medan.

Sugiyono. 2017. Metode Penelitian Bisnis. Bandung : Alfabeta

Sugiyono. 2012. Statistika Untuk Penelitian. Bandung : Alfabeta.

Sutrisno Edi. 2009. Manajemen Sumber Daya Manusia. Ed. I. Cetakan. I. Jakarta : Kencana Prenada Media Group.

Umar Husein. 2004. Metode Penelitian Untuk Skripsi dan Tesis Bisnis. Jakarta : Raja Grafindo Persada.

Vita Ina Vauzia.2017. Pengaruh Pelatihan dan Disiplin Kerja Terhadap Kinerja Karyawan PT. Pos Indonesia Kabupaten Jember. Skripsi Universitas Muhammadiyah Jember.

Zainal Fudin. 2013. Pengaruh Disiplin Kerja Terhadap Kinerja Karyawan pada PT. Rekatama Putra Gegana Bandung. Skripsi Universitas Wiyana Mukti Bandung. 